\title{
Avaliação da adesão, qualidade e aceitabilidade da alimentação escolar entre os alunos das Escolas Municipais de Três Pontas-MG
}

\author{
Assessment of the accession, quality and acceptance of school feeding \\ among students in the Municipal Schools of Three Points-MG
}

Marina MarTins DaniEL Daniele Caroline Faria MOREIRA $^{1}$

${ }^{\mathrm{I} C e n t r o ~ U n i v e r s i t a ́ r i o ~ d o ~ S u l ~ M i n a s ~}$ (UNIS). Varginha/MG - Brasil.

\begin{abstract}
Resumo
O Programa Nacional de Alimentação Escolar (PNAE) é caracterizado como a política pública de maior longevidade do Brasil na área de segurança alimentar e nutricional, que tem como objetivo contribuir para o crescimento, desenvolvimento e formação de hábitos alimentares saudáveis durante a permanência dos alunos no âmbito escolar. A aceitação pelos alunos é um fator determinante para a qualidade do serviço prestado pelas escolas. O objetivo deste trabalho foi conhecer a adesão, frequência, aceitabilidade e qualidade da alimentação escolar. A pesquisa foi realizada nas escolas municipais de Três Pontas-MG. Foram avaliadas a adesão, frequência e aceitação de 271 escolares dos $3^{\circ}$. e $4^{\circ}$. anos do ensino fundamental. Foram constatadas adesão e aceitabilidade de $90,78 \%$ e $97 \%$ respectivamente, sendo consideradas satisfatórias. Foi verificado que mais da metade dos escolares consomem diariamente a refeição ofertada por sua escola. Os cardápios analisados estavam adequados, oferecendo os alimentos recomendados, segundo o método Avaliação Qualitativa das Preparações do Cardápio Escolar (AQPC Escola), com exceção da oferta de leite e derivados e frutas.
\end{abstract}

Palavras-chave: Alimentação Escolar. Aceitabilidade. Adesão.

Abstract The National School Feeding Program (PNAE) is characterized as a public policy of greater longevity in Brazil in the area of food and nutritional security, which aims to contribute to the growth, development and formation of healthy eating habits during the permanence of the students do not shout school. Acceptance by students is a determining factor for the quality of service provided by schools. The objective of this study is to know the adherence, frequency, acceptability and quality of school feeding. A research carried out in the municipal schools of Três Pontas-MG. The adherence, frequency and acceptance of 271 students from the 3rd and 4th years of elementary school were evaluated. Adherence and acceptance of $90.78 \%$ and $97 \%$, respectively, were found to be satisfactory, with more than half of the students consuming a meal from their school daily. The menus analyzed are adequate, offering the foods recommended according to the method qualitative evaluation of school-board preparations (AQPC Escola), with the exception of the supply of milk and dairy products and fruits.

KeYwords: SCHOOL FEEDING. ACCEPTABility. ACCession. 


\section{INTRODUÇÃO}

O Programa Nacional de Alimentação Escolar (PNAE) é caracterizado como a política pública de maior longevidade do Brasil na área de segurança alimentar e nutricional e um dos maiores programas de alimentação escolar no mundo. $\mathrm{O}$ programa tem como objetivo contribuir para o crescimento, desenvolvimento, rendimento escolar e formação de hábitos alimentares saudáveis durante a permanência dos alunos no âmbito escolar. São atendidos alunos da educação infantil, ensino fundamental, médio e educação de jovens e adultos que sejam matriculados em escolas públicas, filantrópicas e entidades comunitárias. ${ }^{4,18}$

As crianças em idade escolar encontram-se em uma fase crítica, onde são susceptíveis a desenvolverem obesidade, uma vez que existe tendência à inatividade física associada ao consumo exacerbado de lanches hipercalóricos e baixo consumo de alimentos ricos em vitaminas, minerais e fibras. Destacam-se também casos de deficiências nutricionais, entre elas, anemia ferropriva e a hipovitaminose A que comprometem o aprendizado do escolar, acometendo tanto populações com dificuldade de acesso quanto populações com ingestão inadequada, sendo cada vez mais comuns casos de crianças obesas com deficiências de micronutrientes. ${ }^{8}$

As práticas alimentares são adquiridas ao longo da vida. Os primeiros anos de vida são primordiais para se estabelecer hábitos alimentares que promovam a saúde do indivíduo. O âmbito onde se tem maior influência na formação desses hábitos é o escolar, pois é um local de convivência e ensino-aprendizagem, em que deve haver um envolvimento dos alunos, professores, funcionários, pais e nutricionistas, participando de forma integrada em estratégias e programas de promo- ção da alimentação saudável, garantindo assim a qualidade das refeições servidas. ${ }^{8}$

Os cardápios da alimentação escolar devem ser elaborados por um nutricionista capacitado, assegurando a oferta de uma alimentação saudável e adequada, atendendo às necessidades nutricionais dos alunos, levando em consideração a variedade dos alimentos, culturas e tradições locais, diversificação agrícola da região e aspectos sensoriais. ${ }^{5}$

Portanto, o cardápio da alimentação escolar deve garantir refeições saborosas, adequadas aos hábitos alimentares e atendendo às necessidades nutricionais dos estudantes. A aceitação pelos alunos é um fator determinante para a qualidade do serviço prestado pelas escolas, sendo a pesquisa de aceitação um instrumento fundamental. ${ }^{13}$ Dessa forma, o objetivo deste trabalho foi investigar qual é o índice de adesão, frequência de consumo e aceitabilidade entre os alunos dos $3^{\circ}$. e $4^{\circ}$. anos do ensino fundamental em escolas municipais da cidade de Três Pontas-MG e avaliar a qualidade da alimentação escolar oferecida pelas escolas.

\section{MATERIAL E MÉtodos}

O estudo foi desenvolvido no município de Três Pontas-MG, tendo sido submetido e aprovado pelo Comitê de Ética em Pesquisa do Centro Universitário do Sul de Minas UNIS-MG (CAE - 72745417.7.0000.5111). Tratou-se de um estudo transversal analítico desenvolvido nas quatro escolas municipais da zona urbana de Três Pontas-MG, nas quais foi realizado um levantamento preliminar do número de alunos matriculados nos $3^{\circ}$. e $4^{\circ}$. anos, sendo averiguados 827 alunos matriculados, contendo escolares do sexo masculino e feminino. A faixa de idade entre eles era de 8 a 10 anos. 
O critério de escolha das escolas foi serem localizadas na zona urbana, facilitando a operação. A opção por trabalhar com escolares na faixa etária de 8 a 10 anos é que nessa fase eles já são aptos para expressar suas opiniões com clareza e liberdade, além de já conseguirem ler sozinhos.

$\mathrm{O}$ instrumento foi elaborado para obter informações sobre a alimentação escolar, com destaque para questões referentes à adesão, frequência e aceitação. $O$ índice de adesão correspondeu à medida percentual de alunos que referiram consumir a alimentação oferecida pela escola. O índice de frequência semanal correspondeu à medida percentual de vezes em que os alunos relataram consumir por semana a alimentação oferecida e o índice de aceitação correspondeu à medida percentual da soma de alunos que mencionaram gostar ou adorar a alimentação escolar.

Para a elaboração do questionário, foram formuladas duas perguntas fechadas referindo-se ao consumo e a frequência, e uma questão aberta como justificativa para o não consumo da alimentação escolar. Para avaliar a aceitabilidade, foi escolhido o método indicado pelo Manual para aplicação dos testes de aceitabilidade do PNAE, ${ }^{3}$ a escala hedônica facial mista, da qual foi adaptada, nela se oferecia a possibilidade de manifestar detestar, não gostar, ser indiferente, gostar ou adorar.

Os Termos de Consentimento Livre e Esclarecido (TCLE) foram encaminhados aos pais, a fim de obter autorização para a participação de seus filhos na pesquisa. Os questionários foram respondidos pelos alunos cujos pais assinaram o TCLE. A pesquisa ocorreu em sala de aula, sob supervisão da professora da turma que foi orientada a não interferir nas respostas dadas pelos alunos.

A avaliação dos cardápios foi realizada por meio do método Avaliação Qualitativa das Preparações do Cardápio Escolar (AQPC Escola), ${ }^{23}$ no qual os cardápios semanais das escolas foram registrados para serem analisados, verificando se atendiam às recomendações sobre a oferta de alimentos recomendados, que podem ser vistos no Quadro 1.

Quadro 1 - Alimentos recomendados pelo método AQPC Escola. ${ }^{23}$

Frutas in natura: todas as frutas frescas e/ou secas, inteiras, fracionadas, com ou sem adição de adição de outros ingredientes;

Saladas: todos os vegetais não amiláceos servidos frios;

Vegetais não amiláceos: flores (brócolis, couve-flor e alcachofra), folhas, caules, brotos (acelga, agrião, alface, almeirão, broto de alfafa e de feijão, chicória, escarola, repolho e rúcula), frutos, raízes e tubérculos não amiláceos (abóbora, abobrinha, berinjela, chuchu, cenoura e beterraba);

Cereais, massas e vegetais amiláceos: cereal matinal sem açúcar e/ou integral, pão, macarrão, arroz, polenta, aipim, mandioca, inhame, batata, cará, torta salgada e bolo caseiro doce sem recheio ou cobertura;

Alimentos integrais: todos os alimentos vegetais sem refinamento;

Carnes e ovos: todas as carnes e ovos;

Leguminosas: todas as leguminosas;

Leite e derivados: todos os tipos de leites, iogurtes, bebidas lácteas e queijos. 
Foi realizada uma análise dos alimentos que compunham as preparações e posteriormente eles foram classificados. Ao finalizar todas as semanas, foi pontuado o número de vezes que cada item apareceu na semana e feito o percentual de acordo com o número de dias analisados. Os cardápios foram registrados no dia da pesquisa com os escolares. Ressaltando que os cardápios semanais foram iguais para toda a rede municipal de ensino da cidade, duas escolas foram avaliadas na mesma semana em horários diferentes, portanto, foram registrados três cardápios ao invés de quatro.

A etapa de pesquisa de campo foi realizada somente após a autorização da Secretaria Municipal de Educação e da direção de cada escola. Os dados coletados foram tabulados em planilhas do Excel e foram analisados de acordo com o padrão de referência do Manual para a aplicação dos testes de aceitabilidade do PNAE. ${ }^{3}$

\section{RESUlTADOS E DISCUSSÃo}

O estudo foi realizado no período de setembro a outubro de 2017. Dos 827 escolares dos $3^{\circ}$. e $4^{\circ}$. anos da rede municipal de ensino da cidade de Três Pontas-MG, participaram da pesquisa um total de 271 escolares $(32,76 \%)$, os demais escolares não participaram devido à não autorização dos pais e/ou responsáveis.

Para avaliar a adesão da alimentação escolar, foi questionado aos alunos se eles consumiam a refeição oferecida pela sua escola, resultados que podem ser vistos na Tabela 1 .
Tabela 1 - Consumo da alimentação escolar relatado pelos escolares dos $3^{\circ}$. e $4^{\circ}$. anos das escolas municipais da cidade de Três Pontas-MG.

\begin{tabular}{|l|c|c|}
\hline Você consome a refeição da escola? & N. & $\%$ \\
\hline SIM & 246 & 90,78 \\
\hline NÃO & 25 & 9,22 \\
\hline Total de escolares & 271 & 100 \\
\hline
\end{tabular}

A porcentagem de escolares que relataram consumir a alimentação escolar foi de $90,78 \%$, resultado semelhante ao estudo realizado na cidade de Itapetinga-BA, em 2015, com três escolas municipais, onde uma das escolas apresentou índice de adesão de $94 \% .{ }^{17}$ Dados que foram superiores ao estudo de Martins et al. ${ }^{14}$ feito na cidade de Piracicaba-SP, onde constou que 77,5\% dos escolares consomem a alimentação escolar. Fatos que podem contribuir para esses altos índices de adesão são: a descentralização do programa, onde permite que as refeições sejam elaboradas conforme os hábitos alimentares de cada município e também a inexistência de ponto de venda de alimentos dentro da escola. ${ }^{19}$

O Manual para aplicação dos testes de aceitabilidade no Programa Nacional de Alimentação Escolar estabeleceu como ponto de corte para avaliar a adesão à alimentação escolar os valores que foram obtidos em um estudo realizado pela Universidade de Campinas, que são divididos em quatro categorias: acima de $70 \%$ alto índice de adesão; $50 \%$ a $70 \%$ médio; $30 \%$ a $50 \%$ baixo e menor que $30 \%$ índice muito baixo de adesão. ${ }^{3}$ Dessa forma, se comprova que o índice de adesão 
da alimentação escolar entre os escolares deste presente estudo é muito satisfatório, alcançando cerca de $91 \%$ dos alunos.

Em relação ao não consumo da alimentação escolar, constatou-se que apenas 9,22\% não consomem, dado semelhante ao encontrado em um estudo realizado nas es- colas municipais na cidade de Palmas-TO, em 2013, o qual apontou que $8,11 \%$ não consumiam a alimentação escolar. ${ }^{12}$

Foi questionado aos escolares que alegaram não consumir a alimentação qual o motivo por essa opção. As respostas dadas por eles podem ser vistas na Figura 1.

Figura 1 - Os motivos relatados pelos escolares ao não consumirem a alimentação escolar, escolares do $3^{\circ}$. e $4^{\circ}$. anos das escolas municipais de Três Pontas, MG.

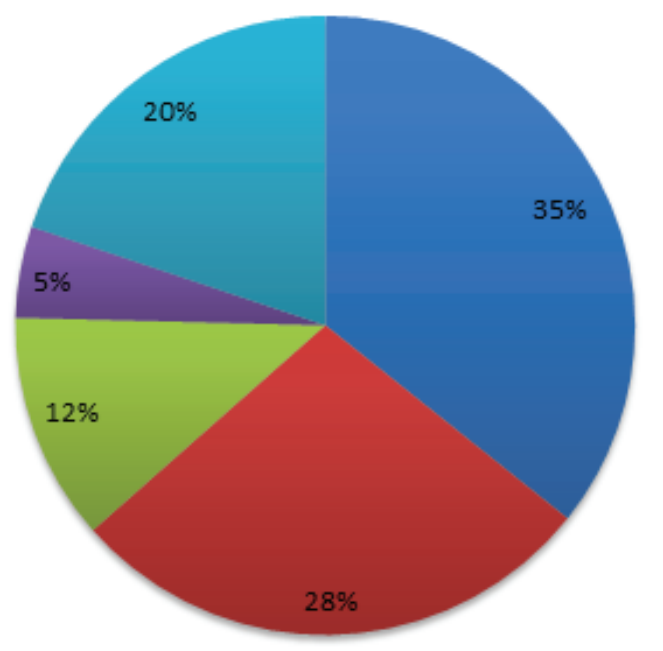

\author{
Trago meu próprio lanche \\ - Porque não gosto \\ Não tenho fome \\ Demoro para comere acaba o \\ recreio \\ Não responderam
}

Ao analisar os motivos alegados pelos escolares para o não consumo da alimentação escolar se destacam os fatos de o escolar levar o seu próprio lanche de casa $(35 \%$; $\mathrm{n}=9$ ) e o de não gostar da refeição ofertada pela escola $(28 \% ; n=7)$. Como no estudo realizado em Canoinhas-SC, ${ }^{15}$ com escolares do $1^{\circ}$ ao $4^{\circ}$ ano, o qual apontou que $62,05 \%$ levam seu lanche de casa e 5,25\% não gostam das refeições da escola. Porém os resultados encontrados por Santos et al. ${ }^{20} \mathrm{em}$ uma escola municipal na cidade de Pelotas-RS, mostraram que (a maioria) 50\% alegaram não consumir pelo fato de não gostar da refeição oferecida pela escola.

Neste presente estudo, onde foram en- trevistados escolares dos $3^{\circ}$ e $4^{\circ}$ anos, houve a prevalência de $63 \%$ da justificativa para não adesão à alimentação escolar para os motivos: "levarem o lanche de casa" e "não gostarem das refeições servidas". Mota e colaboradores ${ }^{15}$ revelam que tais motivos, para o não consumo da alimentação escolar, podem estar relacionados ao desconhecimento por parte dos pais em relação à qualidade das refeições oferecidas na escola ou por opção própria do aluno em preferir brincar no intervalo ao invés de consumir a refeição.

Após avaliar a adesão, foi questionado aos 246 escolares qual a frequência de consumo semanal da refeição escolar. Os resultados podem ser vistos na Figura 2. 
Figura 2 - Frequência de consumo semanal entre os escolares que relataram consumir a alimentação escolar das escolas municipais de Três Pontas-MG.

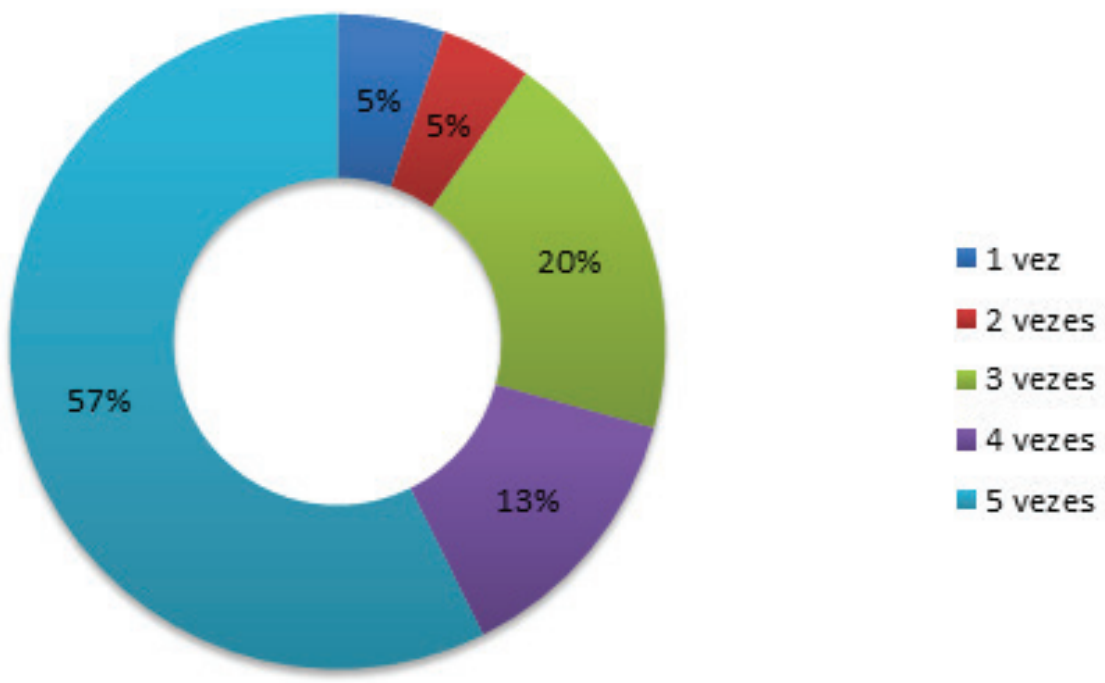

Em relação à frequência de consumo semanal, notou-se que $57 \%$ deles consomem diariamente a refeição ofertada pela escola, dado semelhante à pesquisa de Ferreira et al. ${ }^{12}$ feita na cidade de Palmas-TO que constatou-se que 52,91\% consomem diariamente a merenda escolar. Um estudo realizado por Silva et al. ${ }^{21}$ em dez municípios do Brasil, sendo um entre eles em Minas Gerais, avaliou que os escolares com idade inferior a 11 anos costumam consumir a refeição escolar com maior frequência, chegando em torno de quatro vezes por semana. Fato que confirma ainda mais o resultado obtido neste presente estudo, onde a faixa etária dos escolares estava entre 8 a 10 anos.

Para avaliação da aceitabilidade da alimentação entre os escolares, foi aplicada uma escala hedônica facial mista. A escala permitia que os escolares marcassem a expressão facial na qual se identificavam com a refeição oferecida pela sua escola. Responderam a escala hedônica os escolares que referiram consumir a alimentação escolar entre uma a cinco vezes por semana, os resultados podem ser vistos na Figura 3.

Quanto à aceitação da alimentação escolar por meio da escala hedônica facial, 67\% dos escolares mencionaram adorar e 30\% gostar da alimentação escolar, nenhum aluno relatou detestar ou não gostar da refeição oferecida pela escola, o que significa que o índice de aceitabilidade da alimentação escolar é de 97\%. De acordo com a Resolução/ FNDE/CD nº. 32, o índice de aceitabilidade não deve ser inferior a $85 \%{ }^{6}$

Segundo o Manual para aplicação dos testes de aceitabilidade do PNAE, ${ }^{3}$ para se avaliar a aceitação deve-se utilizar o número de alunos que marcaram as expressões "gostei" e "adorei". Somando-se as duas expressões, a porcentagem obtida deve ser maior ou igual a $85 \%$ para ter uma boa aceitabilidade. Na presente pesquisa, com a soma das duas expressões se obteve a porcentagem de $97 \%$, revelando excelente aceitabilidade da alimentação escolar entre os entrevistados. 
Figura 3 - Aceitabilidade da alimentação escolar pelos escolares dos $3^{\circ}$. e $4^{\circ}$. anos das escolas municipais de Três Pontas-MG por meio da escala hedônica facial mista.

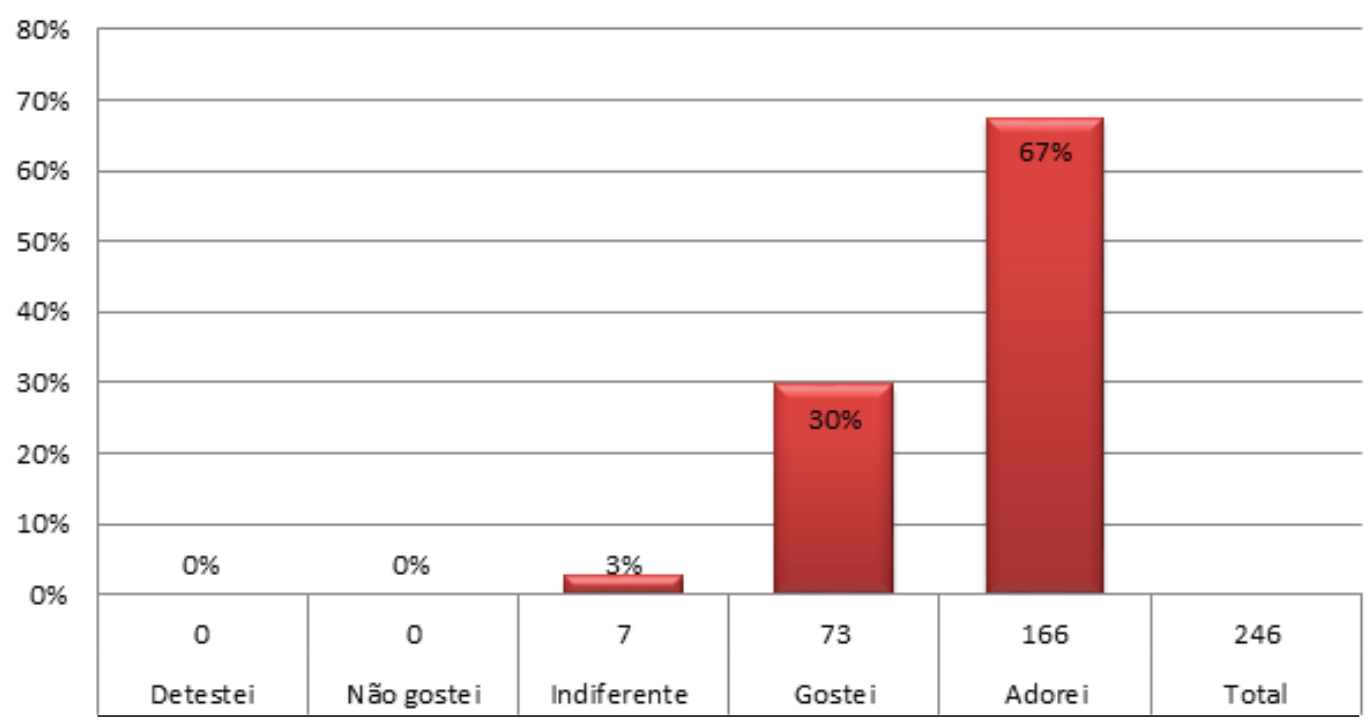

Os estudos de Martins et al., ${ }^{14}$ 2004; Muniz e Carvalho; ${ }^{16}$ Teo e colaboradores; ${ }^{22}$ Basaglia e colaboradores ${ }^{2}$ mostraram outra realidade em relação à aceitabilidade, pois obtiveram resultados de 67\%; 82\%; 70,80\%; $83,95 \%$ respectivamente. Tais registros indicam que a aceitação encontrada na presente pesquisa é alta, tanto na comparação com outros estudos semelhantes como na comparação com a expectativa do Programa.

O Quadro 2 apresenta o cardápio referente às refeições ofertadas pelas escolas durante as três semanas de coleta (não consecutivas) em todos os dias da semana. Também foi realizada uma análise qualitativa dos alimentos ofertados de acordo com o método AQPC Escola ${ }^{23}$ que está demonstrado na Tabela 2.

O método AQPC Escola não define um percentual de adequação, pois depende de fatores como tipo de cardápio, tipo de escola, período de permanência escolar, estrutura físico-funcional da UAN escolar, tipo de contrato (se for o caso), alimentos regionais e sazonalidade. Esse método possibilita realizar uma avaliação qualitativa dos cardápios oferecidos nas escolas, não considerando o número de porções oferecidas diariamente, mas sim um indicador para verificação da presença dos alimentos recomendados. ${ }^{23}$

Segundo a Resolução nº. 38, de 16 de julho, ${ }^{7}$ os cardápios devem oferecer, pelo menos, três porções de frutas e hortaliças por semana, resultado que não foi encontrado nesta pesquisa, não havendo oferta de frutas, somente de hortaliças. Diferente do estudo de Boaventura et al., ${ }^{10}$ realizado na cidade de São Paulo, no qual os cardápios avaliados todos atingiram 100\% referente à oferta de frutas. Já no estudo de Ygnatios e colaboradores ${ }^{24}$ realizado em uma escola privada no interior de Minas-Gerais notou-se que não foi ofertada porção de fruta alguma aos escolares.

O baixo consumo de frutas observado causa uma possível predisposição a defi- 
Quadro 2 - Cardápios oferecidos pelas escolas municipais da cidade de Três Pontas-MG.

\begin{tabular}{|c|c|c|c|c|c|}
\hline Semanas & Segunda-feira & Terça-feira & Quarta-feira & Quinta-feira & Sexta-feira \\
\hline Semana 1 & $\begin{array}{l}\text { Arroz branco; } \\
\text { Feijão com pedaços } \\
\text { de carne bovina; } \\
\text { Salada de repolho } \\
\text { com beterraba }\end{array}$ & $\begin{array}{l}\text { Arroz branco; } \\
\text { Feijão carioca; } \\
\text { Frango refogado } \\
\text { com batata; } \\
\text { Salada de alface }\end{array}$ & $\begin{array}{l}\text { Arroz branco; } \\
\text { Feijão carioca; } \\
\text { Ovos ao molho; } \\
\text { Salada de cenoura } \\
\text { com brócolis }\end{array}$ & $\begin{array}{l}\text { Macarrão ao } \\
\text { molho de frango; } \\
\text { Feijão carioca; } \\
\text { Salada de alface } \\
\text { com beterraba }\end{array}$ & $\begin{array}{l}\text { Arroz branco; } \\
\text { Feijão carioca; } \\
\text { Carne bovina com } \\
\text { cenoura; } \\
\text { Repolho refogado }\end{array}$ \\
\hline Semana 2 & $\begin{array}{l}\text { Arroz com ovos; } \\
\text { Feijão carioca; } \\
\text { Repolho refogado } \\
\text { com cenoura }\end{array}$ & $\begin{array}{l}\text { Arroz branco; } \\
\text { Feijão carioca; } \\
\text { Frango refogado } \\
\text { com batatas; } \\
\text { Salada de alface }\end{array}$ & $\begin{array}{l}\text { Arroz branco; } \\
\text { Feijão carioca; } \\
\text { Polenta à bolonhesa; } \\
\text { Salada de alface com } \\
\text { beterraba }\end{array}$ & $\begin{array}{l}\text { Arroz branco; } \\
\text { Tutu com iscas } \\
\text { suínas; } \\
\text { Salada de cenoura } \\
\text { com tomate }\end{array}$ & $\begin{array}{l}\text { Arroz branco; } \\
\text { Feijão carioca; } \\
\text { Macarrão ao molho } \\
\text { de soja; } \\
\text { Salada de alface } \\
\text { com beterraba }\end{array}$ \\
\hline Semana 3 & $\begin{array}{l}\text { Arroz branco; } \\
\text { Feijão carioca; } \\
\text { Ovos ao molho; } \\
\text { Repolho refogado } \\
\text { com cenoura }\end{array}$ & $\begin{array}{l}\text { Arroz branco; } \\
\text { Feijão carioca; } \\
\text { Polenta à } \\
\text { bolonhesa; } \\
\text { Salada de alface } \\
\text { com tomate }\end{array}$ & $\begin{array}{l}\text { Macarrão com } \\
\text { molho de frango; } \\
\text { Feijão carioca; } \\
\text { Salada de alface com } \\
\text { beterraba }\end{array}$ & $\begin{array}{l}\text { Arroz branco; } \\
\text { Feijão carioca; } \\
\text { Iscas de pernil com } \\
\text { batata; } \\
\text { Salada de cenoura }\end{array}$ & $\begin{array}{l}\text { Galinhada; } \\
\text { Feijão carioca; } \\
\text { Salada de repolho }\end{array}$ \\
\hline
\end{tabular}

Tabela 2 - Análise qualitativa dos cardápios oferecidos pelas escolas municipais de Três Pontas-MG, por intermédio do método AQPC Escola.

\begin{tabular}{|l|c|c|c|l|l|l|l|l|l|}
\hline Semanas & Dias & Frutas & Saladas & $\begin{array}{l}\text { Vegetais } \\
\text { não } \\
\text { amiláceos } \\
\text { massas e } \\
\text { vegetais } \\
\text { amiláceos }\end{array}$ & $\begin{array}{l}\text { Cereais, } \\
\text { integrais }\end{array}$ & $\begin{array}{l}\text { Alimentos } \\
\text { e ovos }\end{array}$ & Leguminosas & $\begin{array}{l}\text { Leites } \\
\text { e derivados }\end{array}$ \\
\hline Semana 1 & 5 & 0 & 4 & 2 & 6 & 3 & 5 & 5 & 0 \\
\hline Semana 2 & 5 & 0 & 4 & 2 & 8 & 4 & 4 & 6 & 0 \\
\hline Semana 3 & 5 & 0 & 4 & 3 & 6 & 5 & 5 & 5 & 0 \\
\hline TOTAL & 15 & 0 & 12 & 7 & 20 & 12 & 14 & 16 & 0 \\
\hline$\%$ & $100 \%$ & $0 \%$ & $80 \%$ & $58,33 \%$ & $100 \%$ & $80 \%$ & $93,33 \%$ & $100 \%$ & $0 \%$ \\
\hline
\end{tabular}


ciências nutricionais específicas, como hipovitaminose A, anemia ferropriva e doenças crônicas não-transmissíveis (DCNT) ${ }^{11}$ Segundo Barreto et al., ${ }^{1}$ os hábitos alimentares associados a maior ingestão de frutas e vegetais são fatores protetores ao desenvolvimento de obesidade. Dessa forma, uma alimentação saudável desde a infância é um fator que contribui para a promoção da saúde na vida adulta.

As saladas são contabilizadas separadamente no AQPC Escola. A presença de saladas não visa somente aumentar o consumo de vegetais, mas também influenciar de modo positivo a formação de hábitos alimentares mais saudáveis. O papel da escola é essencial, pois além de ofertar alimentos nutricionalmente adequados, também promove a saúde e hábitos alimentares saudáveis desde a infância. ${ }^{23}$ Dessa forma, as escolas avaliadas estão fazendo seu papel para a formação de hábitos alimentares saudáveis de seus escolares, pois foram constatados $80 \%$ de oferta nesse grupo.

Quanto à oferta de proteína animal, nota-se que somente um dia não esteve presente a oferta proteica, porém a mesma foi substituída por uma proteína vegetal. É importante destacar que não houve preparações proteicas fritas, sendo um fator positivo na promoção à saúde e formação de hábitos alimentares dos escolares. As proteínas desempenham um papel essencial no corpo humano, principalmente nas crianças, por estarem em fase de crescimento. ${ }^{21}$

Analisando a ausência da oferta de leite e derivados, deve-se destacar que o tempo de permanência dos escolares foi de apenas meio período, sendo mais comum a oferta de leite para os pré-escolares, que fazem cin- co refeições diárias no período escolar, pois permanecem por período integral. ${ }^{10}$ Porém, o PNAE não estabelece a frequência de consumo semanal nem a quantidade de porções que devem ser servidas para os pré-escolares de alimentos do grupo dos laticínios.

Vale destacar o fato de não ter sido ofertado alimentos ultraprocessados aos escolares, conforme preconiza o Ministério da Saúde. O Guia Alimentar para População Brasileira recomenda que os alimentos ultraprocessados sejam evitados, por serem alimentos nutricionalmente desbalanceados. Sua forma de produção envolve diversas técnicas de processamento, além da inclusão de ingredientes como sal, açúcar, óleos e gorduras, carboidratos, proteínas e substâncias sintetizadas a partir de petróleo e carvão, entre outras fontes. ${ }^{9}$

Os demais alimentos estiveram presentes em todas as semanas nas escolas avaliadas. Diante disso, notou-se que os cardápios das escolas urbanas municipais da cidade de Três Pontas-MG estavam adequados, pois ofereceram aos escolares os alimentos recomendados, segundo o método AQPC Escola, com exceção do leite e seus derivados, e na oferta de frutas, que devem atentar para que assim possam atender melhor às necessidades dos escolares.

\section{CONSIDERAÇões FINAIS}

Concluiu-se que o nível de adesão ao Programa Nacional de Alimentação Escolar foi elevado. Já em relação à frequência, cerca de metade dos escolares relataram consumir os alimentos diariamente. A aceitabilidade da alimentação pelos escolares 
ultrapassou o preconizado pelo programa, sendo considerada excelente. Sobre a qualidade da alimentação ofertada, os cardápios desenvolvidos para os escolares das escolas municipais de Três Pontas-MG apresentaram baixa oferta de frutas e leite e seus derivados e uma oferta adequada de saladas, vegetais, leguminosas, carnes e ovos.

\section{REFERÊNCIAS}

1. Barreto SM, Pinheiro ARO, Sichieri R., Monteiro CA, Filho MB, Schimidt MI et al. Análise da Estratégia Global para Alimentação, Atividade Física e Saúde, da Organização Mundial da Saúde. Epidemiologia e Serviços de Saúde. 2005; 14 (1): 41-68.

2. Basaglia P., Marques AS, Benatti L. Aceitação da merenda escolar entre alunos da rede estadual de ensino da cidade de Amparo-SP. Unisepe - Saúde em Foco. 2015; (7): 126-38.

3. Brasil. Centro colaborador em alimentação e nutrição Escolar. Fundo Nacional de Desenvolvimento da Educação CECANE - UNIFESP. Manual para aplicação dos testes de aceitabilidade no Programa Nacional de Alimentação Escolar (PNAE), 2010, 56 p.

4. Brasil. Fundo Nacional de Desenvolvimento da Educação. Ministério da Educação. Sobre o PNAE, 2012. Disponível em: http://www.fnde.gov.br/programas/alimentacao-escolar. Acesso em: 30 de mar. 2017.

5. Brasil. Fundo Nacional de Desenvolvimento da Educação, 2012. Disponível em: http://www. fnde.gov.br/programas/pnae/pnae-eixos-de-atuacao/pnae-alimentacao-e-nutricao?tmpl=comp onent\&print=1/. Acesso em: 30 de mar. 2017.

6. Brasil. Ministério da Educação. Fundo Nacional de Desenvolvimento da Educação. Conselho Deliberativo. Resolução/FNDE/CD no. 32 de agosto de 2006. Disponível em: ftp://ftp.fnde.gov. br/web/resolucoes_2006/res032_10082006.pdf.

7. Brasil. Ministério da Educação. Fundo Nacional de Desenvolvimento da Educação. Conselho deliberativo. Resolução no. 38, de 16 de julho de 2009. Disponível em: https://www.fnde. gov.br/fndelegis/action/UrlPublicasAction.php?acao=getAtoPublico\&sgl_tipo=RES\&num _ ato $=00000038 \&$ seq_ato $=000 \& v l r \_a n o=2009 \&$ sgl_orgao $=C D / F N D E / M E C$.

8. Brasil. Ministério da Educação. Manual de orientação para a Alimentação Escolar na Educação Infantil, Ensino Fundamental, Ensino Médio e na Educação de Jovens e Adultos. Brasília, 2012, 50 p.

9. Brasil. Ministério da Saúde. Guia Alimentar Para a População Brasileira. Brasília, 2014, 152 p.

10. Boaventura PS, Oliveira AC, Costa JJ, Moreira PVP, Matias ACG, Spinelli MGN et al. Avaliação qualitativa de cardápios oferecidos em escolas de educação infantil da grande São Paulo. Demetra: Alimentação, Nutrição \& Saúde, 2013; 8 (3): 397-409.

11. Conceição SIO, Santos CJN, Silva AAM, Silva JS, Oliveira TC. Consumo alimentar de escolares das redes pública e privada de ensino em São Luís, Maranhão. Rev. Nutr. 2010; 23 (6): 993-1.004.

12. Ferreira NC, Sales GS, Coelho FB, Moreira RAM, Schott E., Martins MLB. Aceitabilidade da alimentação oferecida pelo programa nacional de alimentação escolar no município de Palmas-TO. UnirG - Revista Cereus, 2015; 7 (2): 133-50.

13. Flávio EF, Barcelos MFP, Lima AL. Avaliação química e aceitação da merenda escolar de uma escola estadual de Lavras-MG. Ciên. agrotec., 2004; 28 (4): 840-7.

14. Martins RCB, Medeiros MAT, Ragonha GM, Olbi JH, Segatti MEP, Osele MR. Aceitabilidade da Alimentação Escola no Ensino Público Fundamental. Saúde Rev. 2004; 6 (13): 71-8.

15. Mota CH, Mastroeni SSB, Mastroeni MF. Consumo da refeição escolar na rede pública municipal de ensino. R. bras. Est. pedag., 2013; 94 (236): 168-84. 
16. Muniz VM, Carvalho AT. O Programa Nacional de Alimentação Escolar em município do estado da Paraíba: um estudo sob o olhar dos beneficiários do Programa. Rev. Nutr. 2007; 20 (3): 285-96.

17. Nascimento MCPS. Alimentação escolar em três escolas públicas no município de Itapetinga - BA: uma contribuição para educação ambiental. [Dissertação]. Universidade Estadual do Sudoeste da Bahia. Itapetinga, 2015.

18. Peixinho AML. A trajetória do Programa Nacional de Alimentação Escolar no período de 20032010: relato do gestor nacional. Ciênc. saúde coletiva, 2013; 18 (4): 909-16.

19. Rossi CE, Formentini FS, Ferreira AM. Adesão às refeições oferecidas pelo Programa Nacional de Alimentação Escolar em uma cidade do sudoeste do Paraná. Segur. Aliment. Nutr. 2014; 21(2): 518-26.

20. Santos AP, Pinheiro CT, Maciel FV, Geier JM. Adesão ao programa nacional de alimentação escolar por Estudantes de uma escola municipal de Pelotas-RS. XIX CIC - XII ENPOS - Mostra Científica 2010. Disponível em: http://www2.ufpel.edu.br/cic/2010/cd/pdf/CS/CS_01164.pdf.

21. Silva MV, Sturion GL, Ometto AMH, Pipitone MAP, Furtuoso MCO. Estado nutricional de escolares e seu acesso a programas sociais em dez municípios brasileiros. Nutrire: rev. Soc. Bras. Alim. Nutr., 2002; 23: 33-53.

22. Teo CRPA, Corrêa EN, Gallina LS, Fransozi C. Programa nacional de alimentação escolar: adesão, aceitação e condições de distribuição de alimentação na escola. Nutrire: rev. Soc. Bras. Alim. Nutr., 2009; 34 (3): 165-85.

23. Veiros MB, Martinelli SS. Avaliação Qualitativa das Preparações do Cardápio Escolar - AQPC Escola. Nutrição em Pauta, 2012; 20 (114): 2-13.

24. Ygnatios NTM, Lima NN, Pena GG. Avaliação qualitativa das preparações do cardápio de uma escola privada em um município do interior de Minas Gerais. Rasbran - Revista da Associação Brasileira de Nutrição, 2017; 8 (1): 82-9.

\section{DAdos DAS AUTORAS}

\section{Marina Martins Daniel}

Graduação em Nutrição pelo Centro Universitário do Sul de Minas (UNIS). Nutricionista. Três Pontas/MG-Brasil. marinamdaniel@outlook.com

\section{Daniele Caroline Faria Moreira}

Graduação em Nutrição pela Universidade Federal de Alfenas (UNIFAL). Mestrado em Saúde e Nutrição pela Universidade Federal de Ouro Preto (UFOP). Nutricionista. Docente no curso de Nutrição do Centro Universitário do Sul Minas (UNIS). Varginha/MG - Brasil. danielefariamoreira@gmail.com

Submetido em: 25-6-2018

Aceito em: 22-5-2019 